\title{
Marital Conflict and Boys' Peer Relationships: The Mediating Role of Mother-Son Emotional Reciprocity
}

\author{
Eric W. Lindsey \\ Texas Tech University \\ Jessica Campbell \\ National Institute on Drug Abuse
}

\author{
Carol MacKinnon-Lewis \\ University of South Florida \\ James M. Frabutt \\ University of North Carolina at Greensboro
}

\author{
Michael E. Lamb \\ National Institute of Child Health and Human Development
}

\begin{abstract}
This study examined the role of mother-son emotional reciprocity in connections between marital conflict and the quality of boys' peer relationships. Parents from 84 intact families with preadolescent boys reported on the level of conflict in their marital relationship. Observations of mother-son interaction were coded for emotional reciprocity, and assessments of boys' peer relationships were obtained from both teachers and classmates. No direct connection between marital conflict and boys' peer relationships was observed. Rather, marital conflict affected boys' social competence indirectly, through its effect on the emotions expressed between mother and son. The findings support the proposal that emotional processes play an important role in connections between marital conflict and children's peer relationships and suggest that family emotional expressiveness deserves greater attention in both research and intervention.
\end{abstract}

The quality of children's peer relationships represents one of the best predictors of risk for adjustment problems (Parker \& Asher, 1987). Evidence suggests that children whose peer relationships are characterized by high levels of aggression and who are rejected by peers are more likely to drop out of school, engage in delinquent behavior, and develop mental health problems (for a review see Parker, Rubin, Price, \& DeRosier, 1995), whereas children who are accepted by peers are more likely to succeed in school (Wentzel \& Asher, 1995) and experience positive adult adjustment (Bagwell, Newcomb, \& Bukowski, 1998). In an effort to elucidate the origins of individual differences in the quality of children's peer relationships, and guided by theoretical proposals of connections between children's family

Eric W. Lindsey, Department of Human Development and Family Studies, Texas Tech University; Carol MacKinnon-Lewis, Center for Scholarship in Action, University of South Florida; Jessica Campbell, National Institute on Drug Abuse, National Institutes of Health, Bethesda, Maryland; James M. Frabutt, Center for the Study of Social Issues, University of North Carolina at Greensboro; Michael E. Lamb, National Institute of Child Health and Human Development, National Institutes of Health, Bethesda, Maryland.

This investigation was supported by grants to Carol MacKinnon-Lewis from the National Institute of Mental Health (MH49869), the National Science Foundation (10-004), and the William T. Grant Foundation.

Correspondence concerning this article should be addressed to Eric W. Lindsey, Department of Human Development and Family Studies, P.O. Box 41162, Texas Tech University, Lubbock, Texas, 79409-1162. E-mail: elindsey@ hs.ttu.edu experience and their peer relationships (Hartup, 1979; Youniss, 1980), researchers have turned to examine associations between children's family functioning and their peer competency (e.g., Gottman \& Katz, 1989; MacDonald \& Parke, 1984; Putallaz, 1987). Although the majority of work pertaining to linkages between the family and children's relationships with peers has focused on the parent-child relationship (Parke \& Ladd, 1992; Parke et al., 1989), the interdependent and reciprocal nature of family relationships suggests that other aspects of family functioning may also have significant influence on children's relationships with peers. In fact, connections have been established between the quality of children's sibling relationships and social competence with peers (Dunn, Slomkowski, \& Beardsall, 1994), as well as between interparental functioning and children's peer relations (Belsky, Crnic, \& Gable, 1995; Deal, Halverson, \& Wampler, 1989; Lindsey \& Mize, 2001). Less attention has been paid to the connections between the marital relationship and children's peer relationships.

It has been suggested that the quality of parents' marital relationship has an important impact on the lessons children learn about relationships with others (Jouriles, Farris, \& McDonald, 1991; Katz \& Gottman, 1995). Given that children carry expectations and beliefs about relationships that are learned in their family to relationships outside the family (Hart, Ladd, \& Burleson, 1990; MacKinnon-Lewis, Rabiner, \& Starnes, 1999), the quality of parents' marital relationship is likely to be very important for the relationships that children form with peers. Particular emphasis has been given to the role that marital conflict may play in determining the quality of children's peer relationships. 
Although sparse, evidence suggests that children from maritally distressed homes have negative interactions with friends (Gottman \& Katz, 1989), deviant anger expressions with peers (Jenkins, 2000), and problematic peer relationships (Stocker \& Youngblade, 1999) and are rejected by peers (Strassberg, Dodge, Bates, \& Pettit, 1992). Parke and his colleagues (Parke, Burks, Carson, Neville, \& Boyum, 1994; Parke et al., 2001) suggest that understanding connections between marital conflict and children's peer relationships may be critically important given the significance peer relationships have for children's long-term adjustment. Moreover, these authors join with others (Grych \& Fincham, 1990) who propose that by specifying a particular area of child functioning that is affected by marital conflict, namely, children's social competence with peers, researchers may explicate the processes by which marital conflict is linked to children's adjustment.

Theoretical explanations for connections between marital conflict and children's outcomes focus on both direct and indirect linkages (Davies \& Cummings, 1994; Harold \& Conger, 1997; Osborne \& Fincham, 1996). Direct linkages are relationships between marital conflict and child outcomes that are not mediated by other levels of family functioning. Evidence suggests that marital conflict does have direct effects on children's adjustment (Davies \& Cummings, 1994; Harold, Fincham, Osborne, \& Conger, 1997), including children's peer relationships (Strassberg et al., 1992). Indirect linkages are relations between marital conflict and children's outcomes that are mediated by other facets of family functioning. The existence of indirect effects in connections between marital conflict and children's adjustment outcomes has been well established in the literature and is best represented by the "spillover" hypothesis (Erel \& Burman, 1995). Numerous data suggest that the effects of marital conflict spill over into the parent-child relationship, creating negative patterns of parent-child interaction, which in turn produces problematic behavior in children (Fauber, Forehand, Thomas, \& Wierson, 1990; Grych \& Fincham, 1990; Osborne \& Fincham, 1996). In fact, several reviews of this literature have drawn the conclusion that a large proportion of the impact of marital conflict on child adjustment is arrived at indirectly, through changes and problems in the parent-child relationship (Fincham, 1998; Snyder, 1998). However, theoretical and applied approaches to the study of marital conflict call for greater specificity in defining indirect associations between marriage and children's outcomes (Jouriles \& Farris, 1992). Moreover, given the relatively sparse literature focusing on this area, additional research is needed to identify indirect associations between marital conflict and children's peer relationships.

Davies and Cummings (1994, 1998) used the principles of attachment theory to develop an organized theoretical framework to explain both direct and indirect connections between marital conflict and children's adjustment. Specifically, these authors argued that children may experience increased negative emotional arousal and feelings of insecurity as a result of exposure to marital conflict. It is possible that such experiences can interfere with children's ability to regulate their own emotional state, which evidence suggests contributes to negative peer relationships (Eisenberg et al., 1993; Fabes et al., 1999; Rubin et al., 1995). In addition to this direct effect on children's negative emotional arousal, Davies and Cummings proposed that marital conflict may have indirect effects on children's adjustment by reducing parents' warmth and sensitivity in interactions with their children, thus disrupting the child's ability to form secure emotional attachments with parents. Consequently, children develop a negative internal working model, which guides their behavior in the peer group, leading to negative peer interactions.

Consistent with their proposal, Davies and Cummings (1998) found that higher levels of marital conflict predicted greater negative emotional reactions on the part of children to a conflict situation between their mother and a researcher. In addition, children from families with a history of marital discord were more likely to have negative appraisals of the outcome to hypothetical conflict situations between their parents. Both negative emotional reactions and negative appraisals of conflict outcomes on the part of children were associated with internalizing and externalizing behavior problems. Thus, emotional security processes do appear to mediate connections between marital conflict and children's adjustment outcomes. Further support for the emotional security hypothesis comes from evidence that marital conflict disrupts the emotional climate of the parent-child relationship (Grych \& Fincham, 1990; Harold \& Conger, 1997; Owen \& Cox, 1997). In addition, a growing body of literature suggests that patterns of parent-child emotional expressiveness are linked to the quality of children's peer relationships (Boyum \& Parke, 1995; Eisenberg, Fabes, Schaller, Carlo, \& Miller, 1991). To date, however, there has been no examination of connections between marital conflict, the emotional climate of the parent-child relationship, and children's peer relationships.

Reciprocity of emotions between family members may represent a particularly important process in explaining connections between marital conflict and children's social competence. Specifically, patterns of emotional reciprocity have been linked to problematic marital relationships in that couples who are dissatisfied with their marriage display greater reciprocity of negative affect and less reciprocity of positive affect than more satisfied couples (Gottman, 1979; Levenson \& Gottman, 1983). Moreover, reciprocity of negative affect predicts declines in marital satisfaction over time (Levenson \& Gottman, 1985). Similarly, emotional reciprocity between parent and child has been implicated in children's emotional and social functioning (Denham, Renwick-DeBardi, \& Hewes, 1994). Some authors have gone so far as to suggest that parent-child emotional responsiveness may be a key component of the parent-child relationship that translates to children's peer relationships (Parke, Cassidy, Burks, Carson, \& Boyum, 1992). In support of this argument, Carson and Parke (1996) found that reciprocal, negative affect exchanges between fathers and preschool children were associated with lower levels of social competence as rated by teachers, including lower levels of sharing, a greater tendency to avoid other children, 
and higher levels of verbal and physical aggression. Together, this evidence suggests that emotional reciprocity may serve as a link between the marital relationship, the parent-child relationship, and the quality of children's peer relationships. This hypothesis was examined in the current study.

Evidence suggests that the processes of connections between marital conflict, emotional reciprocity, and children's peer relationships may be particularly salient in the motherson relationship. Specifically, researchers have found that low levels of marital satisfaction on the part of mothers are linked to high levels of reciprocity of negative emotions between mothers and sons (Kerig, Cowan, \& Cowan, 1993). In addition, mothers' parenting has been shown to be more consistently associated with children's social outcomes (Maccoby \& Martin, 1983; Rothbaum \& Weisz, 1994). Furthermore, connections between family relationships and peer relationships have been found to be stronger for boys than for girls (Bierman \& Smoot, 1991; Boyum \& Parke, 1995; MacDonald \& Parke, 1984). Thus, in the present investigation, we focused on the effect of marital conflict on the mother-son relationship. This was done in order to present a more focused examination of the processes outlined above and to maximize the effective utilization of a limited pool of resources. As a result, it is important to note at the outset that the findings are applicable to the motherson relationship only and the processes examined are likely to operate differently in mother-daughter and father-child relationships.

It was the purpose of this study to explore the effect of marital conflict on the quality of boys' peer relationships. In keeping with both Gottman's (1979; Levenson \& Gottman, 1983, 1985) model of emotional expressiveness between husbands and wives and Davies and Cummings' (1994, 1998) emotional security hypothesis, particular attention was given to the possible mediating role of emotional expressiveness between mother and son in connections between marital conflict and peer relationships. Marital conflict was expected to be linked to low levels of positive emotional reciprocity and high levels of negative emotional reciprocity between mothers and sons. In turn, positive emotional reciprocity was expected to be linked to indicators of high-quality peer relationships (i.e., low aggressiveness, high peer preference), whereas negative emotional reciprocity was expected to be linked to indicators of lowquality peer relationships (i.e., high aggressiveness, low peer preference). On the basis of evidence that the effect of marital conflict on children's adjustment is largely mediated through its effect on the parent-child relationship, we expected that patterns of emotional reciprocity would mediate associations between marital conflict and the quality of boys' peer relationships.

\section{Method}

\section{Participants}

Participants were part of a larger study, involving 246 families, which examined boys' adjustment across the family and school context (MacKinnon-Lewis et al., 1994, 1999). Given empirical evidence of more consistent connections between mothers' parenting and children's outcomes, and stronger links between family characteristics and outcomes for boys than for girls (see description above), the larger study focused primarily on the mother-son relationship. Although this focus was based on empirical evidence, the decision was made largely due to considerations of limited resources in terms of funding and personnel. However, questionnaire data were collected from fathers. The participants whose data were examined in the current study consisted of 84 intact families with sons (ages 7 to 9 years, $M=7.8$ years), for whom marital conflict data was available from both mothers and fathers, and classroom sociometric data was available for sons. Of the families from the larger sample who were excluded from analyses, 104 had parents who were divorced, 37 were intact families in which fathers declined to participate, and 21 were families in which sociometric data were unavailable for sons. Of the 84 families who were included in analyses, 54 mothers were European American, and 30 were African American. Six mothers had less than a seventh-grade education, 9 had graduate degrees, and the mean level of education was 13 years. The average family income was $\$ 25,000$ per year. Preliminary findings revealed no differences between the intact families participating in the present study and the single-mother families in the larger sample on the primary variables of interest (i.e., marital conflict, mother-son emotional reciprocity, boys' aggression with peers and boys' social competence). Moreover, there were no differences between African American and European American families or between higher and lower socioeconomic status families (based on an index reflecting father's education level). Nor were there differences between the intact families who were and were not included in the present sample.

\section{Procedure}

Mothers and children visited the research laboratory on two occasions approximately 1 week apart, with each session lasting about $90 \mathrm{~min}$. At the beginning of the first session, the study was described in detail and written consent was obtained from both mother and son. Mothers and sons were then escorted to separate rooms where they completed a variety of questionnaires. Mothers completed the Conflict Tactics Scale (CTS; Straus, 1979) and the Family History Inventory (MacKinnon-Lewis, Lamb, Arbuckle, Baradaran, \& Volling, 1992). Once the questionnaires were completed, mother-son dyads were reunited to participate in a competitive interaction activity in which they played the board game Trouble. In the second session, mother-son dyads participated in a cooperative interaction activity in which they were asked to jointly duplicate a figure drawn with an Etch-A-Sketch. Mothers were given $\$ 35$ and boys were given several prizes as compensation for their participation. Following the second laboratory visit, fathers of the participating children were contacted and asked if they would be willing to complete a series of questionnaires. A packet of questionnaires, which included the Conflict Tactics Scale (CTS; Straus, 1979), was sent by mail to the fathers who agreed to participate. Approximately 9 weeks after the laboratory visits, researchers visited children's classrooms where teachers rated children's social competence with peers using the Taxonomy of Problematic Social Situations (Dodge, McClaskey, \& Feldman, 1985) and classmates provided sociometric data on the target children.

Family demographics. Each mother described the demographic characteristics of the family (e.g., maternal education, paternal education, and income) using the Family History Inventory (MacKinnon-Lewis et al., 1992). 
Marital conflict. The Conflict Tactics Scale (CTS) is an 18item questionnaire designed to measure, with three subscales, the use of physical aggression, verbal aggression, and reasoning in response to conflict (Straus, 1979, 1990). Because our interest was in assessing the level of marital conflict, only the 8-item physical aggression scale and the 5-item verbal aggression scale were retained. Both mothers and fathers reported how frequently during the past year and prior to the past year they engaged in or witnessed certain behaviors on a 7-point scale, ranging from never (1) to more than 20 times (7). The instrument was given iteratively for four paired comparisons: the father to mother, the mother to father, the parent to child, and the child to parent. Because our interest focused on marital conflict, only the data concerning father-to-mother and mother-to-father conflict is used in the present study. Coefficient alphas for the Physical Aggression and Verbal Aggression subscales in the present study ranged from .53 to .91, with a median alpha value of .71. Comparisons of the raw score means of the Physical Aggression and Verbal Aggression scales for husbands and wives with those reported from samples involved in validating the CTS measure (Straus, 1990) suggested that the incidence of both forms of marital aggression may be somewhat low in our sample.

Correlations among the mother and father marital conflict subscales revealed low to moderate correlations ( $r$ s ranged from .29 to .45 , mean $r=.38$ ). Because we were interested in retaining separate assessments of marital conflict displayed by husband and wife, and in order to create more valid measures of marital conflict, scores for conflict directed toward a particular partner were averaged across husband and wife. Therefore, wife's marital conflict score represented the wife's aggressive behaviors (verbal and physical) toward the husband (as reported by the wife and husband) and husband's marital conflict represented the husband's hostile behaviors (verbal and physical) toward the wife (as reported by the husband and wife). The coefficient alpha for the resulting marital conflict scores was .72 and .77 , for wives and husbands, respectively.

\section{Observed Behavior}

Mother-son interaction. Using procedures similar to Brody, Stoneman, and MacKinnon (1986), videotapes of the mother-son interaction sessions were coded in real time for the following behaviors on the part of both mothers and sons: negative verbals, negative affects, negative physicals, positive verbals, positive affects, positive physicals, and neutral behavior. For the purpose of the present study, only mother and child expressions of affect were of interest. Positive affect was defined as any facial expression denoting positive emotions, such as smiling, laughing, and giggling, whereas negative affect was any facial expression denoting negative emotions, such as frowning, crying, anger, disgust, and face making. Coders noted the type of emotion (positive, negative) as well as who displayed the emotion (mother, son). It was possible for mother and son to display an emotion at the same time. It is important to note that neither intensity of emotion nor duration of emotion were recorded; rather coders identified the presence of an emotional event when it occurred. Thus, resulting codes represented a count of emotional behavior by a particular partner. Emotional events were delineated from one another by the passage of at least $30 \mathrm{~s}$ without a particular individual displaying a similarly valenced emotion.

Observers had been trained by using videotapes of similar interactions until interobserver reliability, assessed by the percentage of agreements on the behavior-by-behavior coding of the interactions, reached $90 \%$. Reliability was rechecked weekly on $25 \%$ of the sessions. Percentage agreement across all codes aver- aged $91 \%$ in these assessments, with an average kappa of .79 (Cohen, 1960).

Because mother and child affect expressions in the two sessions were highly correlated $(r=.80$ and $r=.76$ for mother and son, respectively), data were combined to create scores based on the total period of interaction. Instances of affect expression, both positive and negative, were summed for both mother and son. Separate positive and negative affect expression scores were created for each partner by dividing the amount of positive and negative affect by the total duration of the interaction period. The resulting scores represented the frequency of positive or negative affect expressed by a particular partner per minute of the interaction session (the average duration of mother-son interaction was 38.23 minutes, with a range of 34.54 to 40.00 minutes). Thus, both mother and son had two emotion scores: frequency of positive affect and frequency of negative affect.

Sequential analysis of mother-son emotional reciprocity. A series of sequential analyses were performed to generate Yule's $Q$ scores, reflecting contingencies in mother-son emotional exchanges (Bakeman, 1991). The resulting Yule's $Q$ scores reflected the probability that a particular event or sequence occurred in relation to other events that might occur. Yule's $Q$ is an oddslikelihood ratio based on a $2 \times 2$ table that compares the probability of a particular sequence occurring (antecedent A followed by consequent B) in relationship to the other events that might occur (e.g., A and not B). A positive $Q$ score indicates that the event sequence of interest (A followed by B) was more likely to occur than other sequences. A negative $Q$ score indicates that the event sequence was less likely to occur. Because it was of interest to account for both mother and child contributions to patterns of emotional reciprocity, the data were examined for several event sequences or co-occurrences, including (a) son positive affect followed by mother positive affect (mother positive emotional reciprocity), (b) son negative affect followed by mother negative affect (mother negative emotional reciprocity), (c) mother positive affect followed by son positive affect (son positive emotional reciprocity), and (d) mother negative affect followed by son negative affect (son negative emotional reciprocity). The resulting $Q$ scores were used in subsequent analyses.

\section{Children's Social Competence}

Sociometric ratings. Using a procedure developed by Coie, Dodge, and Coppotelli (1982), we obtained sociometric peer nominations from boys and their classmates. Each child was presented a roster containing an alphabetized list of all children in their class with accompanying identification numbers. To ensure confidentiality, we requested that the children use only identification numbers in their responses. They were asked to nominate from class rosters the "three children you like least in the class," and the "three children you like most in the class." All of the children (boys and girls) within each class participated. The sociometric nominations were solicited in a group setting; however, because a few children had difficulty completing the task in this format, it was administered to them in an individual setting. Four research assistants visited each classroom to ensure that individual attention was available.

The number of nominations that each child received was standardized within classroom. From these data, a social preference score was created for each child by subtracting their "liked least" standardized score from their "liked most" standardized score and restandardizing the difference.

Assessment of aggressive behavior. Both teachers and peers provided information concerning boys' aggressive behavior. First, children were asked to nominate three classmates who fight a lot. 
The number of nominations received by each child was summed, and scores were standardized within classrooms. Peer nominations for fighting have been shown to be stable across a 5-year period (Coie \& Dodge, 1983), and to have high predictive validity (Kupersmidt \& Coie, 1990).

Second, teachers rated the target children and their classmates by using the Taxonomy of Problematic Social Situations for Children (TOPS) Questionnaire (Dodge, McClaskey, \& Feldman, 1985). The TOPS is a 60-item questionnaire in which the teacher uses 5 -point scales $(1=$ never, $2=$ rarely, $3=$ sometimes, $4=$ usually, 5 = almost always) to indicate how much of a problem each of the specified situations would represent for the child (e.g., "When a peer accidentally hurts this child he/she overreacts with anger and fighting"; "This child uses physical force in order to dominate other kids"). Two of the eight subscale scores reflect children's reactive aggression and proactive aggression with peers. The two scales were summed to create a measure of peer aggression for each child ( $\alpha=.87)$. Dodge et al. (1985) reported that the test-retest reliability on the entire measure ranges from .57 to .72 for factor scores and is .79 for the total score. The mean, standard deviation, and range of scores in this sample were 34.63, 16.16, and 16 to 75 , respectively.

To create an internally consistent multi-item composite measure of boys' peer aggression, correlations were computed between the two measures of boys' peer aggression (i.e., $z$ score of peer nominations for starts fights, and teacher rating of aggression with peers). Results revealed that the two measures were moderately correlated $(r=.46, p<.01)$; thus, these items were summed to yield an internally consistent measure of boys' peer aggression $(\alpha=.79)$.

\section{Results}

\section{Descriptive Analyses}

As can be seen in Table 1, mothers were reported to display more marital conflict than fathers, and this difference was statistically significant, $F(1,84)=5.12, p<.05$. During the mother-son interaction session, positive emotions were more frequent than negative emotions. Sons displayed more emotion than mothers, and this difference was statistically significant for positive $F(1,84)=11.22$, $p<.01$, and negative emotions, $F(1,84)=4.34, p<.05$. Both mothers and sons were more likely to reciprocate their partner's positive emotions than negative emotions.

\section{Correlations Among Measures}

Pearson product-moment correlations were computed to examine the relations among measures of verbal and physical aggression displayed by husbands and wives, the frequency of mother and son emotions, measures of emotional reciprocity, boys' peer aggression, and boys' peer acceptance (see Table 2). These analyses revealed a significant association between husbands' and wives' level of verbal and physical aggression in their marriage. In addition, mothers who displayed more frequent positive emotions also displayed frequent negative emotions when interacting with their son. There were no associations between the frequency of positive and negative emotions expressed by sons. Boys who were more aggressive with peers were more likely to be disliked by peers.

Patterns of associations between emotional expressiveness variables revealed that, within dyads, mothers and sons displayed similar levels of positive and negative emotion. Mothers and sons also displayed similar levels of emotional reciprocity. Correlations between marital conflict measures and mother-son emotional expressiveness variables revealed that in families where husbands were more verbally and physically aggressive toward their wives, mothers displayed more frequent negative emotions during the motherson interaction session. In addition, mothers who displayed high levels of verbal and physical aggression toward their husbands had sons who displayed less frequent positive emotions during their interaction together. There were no other associations between measures of marital conflict and individual frequencies of mother and son emotions. However, correlations between marital conflict and emotional reciprocity measures revealed that mothers who displayed

Table 1

Descriptive Statistics for Measures of Marital Conflict, Frequency of Mother and Son Emotional Expressiveness, Mother and Son Reciprocity of Emotion, and Boys' Aggression and Peer Acceptance

\begin{tabular}{lccc}
\hline \multicolumn{1}{c}{ Measure } & $M$ & $S D$ & Range \\
\hline Marital conflict & & & \\
$\quad$ Mother's verbal and physical aggression & 2.49 & 2.60 & 0.00 to 18.00 \\
$\quad$ Father's verbal and physical aggression & 1.89 & 1.85 & 0.00 to 12.00 \\
Mother and son emotion (frequency) & & & \\
$\quad$ Mother positive emotion & 0.93 & 0.47 & 0.08 to 2.55 \\
$\quad$ Mother negative emotion & 0.13 & 0.11 & 0.00 to 0.55 \\
$\quad$ Son positive emotion & 1.55 & 0.71 & 0.18 to 1.55 \\
$\quad$ Son negative emotion & 0.24 & 0.23 & 0.00 to 1.18 \\
Emotional reciprocity (Yule's $Q$ score) & 0.76 & 0.23 & 0.19 to 0.88 \\
$\quad$ Mother positive emotional reciprocity & 0.12 & 0.14 & 0.21 to 0.42 \\
$\quad$ Mother negative emotional reciprocity & 0.62 & 0.18 & 0.27 to 0.79 \\
$\quad$ Son positive emotional reciprocity & 0.09 & 0.11 & 0.17 to 0.33 \\
$\quad$ Son negative emotional reciprocity & & & \\
Boys' outcomes & 30.52 & 14.39 & 16.00 to 75.00 \\
$\quad$ Aggression with peers & 0.11 & 0.79 & -2.38 to 2.04 \\
$\quad$ Peer acceptance &
\end{tabular}




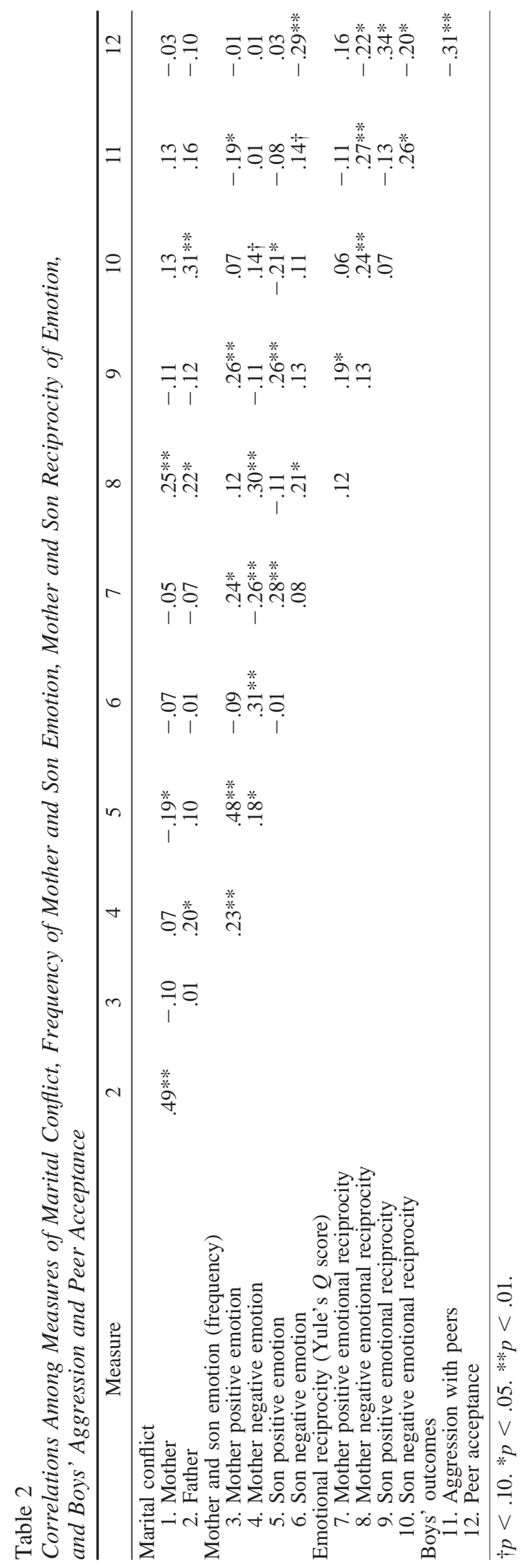

high levels of verbal and physical aggression toward their husbands were more likely to reciprocate sons' negative emotions during the mother-son interaction session. In families where husbands displayed high levels of verbal and physical aggression toward their wives, mothers were more likely to reciprocate sons' negative affect and sons were more likely to reciprocate mothers' negative affect during the mother-son interaction session.

There was no association between marital conflict measures and boys' aggression with peers or boys' social competence with peers. Mothers who displayed more frequent positive emotions during the mother-son interaction session had sons who were less aggressive. Boys who displayed frequent negative emotions with their mother were more aggressive with peers. Boys whose mother reciprocated their negative emotions were less liked by peers and were more aggressive. Boys who reciprocated their mothers' positive emotions were better liked by peers, whereas boys who reciprocated mothers' negative emotions were more aggressive and were less liked by peers.

\section{Examining the Relative Contribution of Mother-Son Reciprocity to Boys' Social Competence}

The correlational analyses presented in the preceding section indicated several associations between mother-son emotional reciprocity variables and measures of boys' peer relationship quality. It was possible, however, that these significant correlations could be attributable to associations between assessments of the frequency of mother and son emotions and peer relationship measures rather than reciprocity per se. To rule out this possibility, we conducted a series of hierarchical multiple regression analyses with each peer relationship measure. Separate analyses were conducted with positive and negative emotion variables. We examined whether measures of emotional reciprocity additively and incrementally predicted children's peer competency. The frequency of mother emotion (positive or negative) was entered in the first step. The frequency of sons' emotion (positive or negative) was entered in the second step. Measures of emotional reciprocity (mother to son, son to mother) were entered simultaneously in the third step. The analyses are summarized in Table 3.

In the analyses involving measures of positive emotion, boys' peer aggression was associated with a low frequency of positive affect on the part of mothers. Peer liking was associated with son's reciprocity of mother's positive affect. Moreover, son's reciprocity of positive affect accounted for unique variance in social preference after taking into account the frequency of mother and son positive affect.

In the analyses involving measures of negative emotion, boys' peer aggression was associated with a high frequency of negative affect displayed by sons when interacting with their mother and by both mother's reciprocity of son's negative affect and son's reciprocity of mother's negative affect. The contribution of the reciprocity scores was significant even after controlling for the frequency of mother and son negative affect. In addition, boys' peer preference 
Table 3

Summary of Regression Analyses for Relations Between Frequency of Mother and Son Expression of Emotions, Mother and Son Emotional Reciprocity, and Boys' Aggression and Peer Acceptance

\begin{tabular}{|c|c|c|c|c|c|c|}
\hline \multirow[b]{2}{*}{ Variable } & \multirow{2}{*}{$\frac{\text { Step } 1}{\text { Mother emotion }}$} & \multirow{2}{*}{$\frac{\text { Step } 2}{\text { Son emotion }}$} & \multicolumn{2}{|c|}{ Step 3} & \multirow[b]{2}{*}{$R^{2}$} & \multirow[b]{2}{*}{$F$ for $R^{2}$} \\
\hline & & & $\begin{array}{l}\text { Mother emotion } \\
\text { reciprocity }\end{array}$ & $\begin{array}{l}\text { Son emotion } \\
\text { reciprocity }\end{array}$ & & \\
\hline \multicolumn{7}{|c|}{ Positive emotion } \\
\hline Aggression with peers & -.21 & -.12 & -.13 & -.09 & .03 & 1.94 \\
\hline Peer acceptance & .15 & -.06 & -.17 & $.29 * *$ & .04 & 2.00 \\
\hline \multicolumn{7}{|c|}{ Negative emotion } \\
\hline Aggression with peers & .10 & $.20 *$ & $.21 *$ & $.22 *$ & .07 & 2.58 \\
\hline Peer acceptance & -.14 & $-.33 * *$ & -.15 & .13 & .02 & 1.62 \\
\hline
\end{tabular}

Note. $\quad$ Values represent standard partial beta after controlling for ethnicity. $R^{2}$ refers to change in $R$ for respective mother-child emotional reciprocity score after controlling for ethnicity and frequency of mother and child emotional expressiveness.

$* p<.05$. **p $<.01$

was associated with a low frequency of negative affect on the part of sons.

\section{Linkages Among Marital Conflict, Mother-Son Emotional Reciprocity, and Boys' Peer Aggression and Social Preference With Peers}

Using multiple regression procedures (Pedhazur, 1982), we conducted path analyses to examine the linkages between marital conflict, mother-son emotional reciprocity, and boys' peer relationships. Because correlation analyses revealed no direct associations between marital conflict and boys' outcomes, only a single path model was generated to examine possible indirect connections between marital conflict and boys' outcomes mediated by mother-son emotional reciprocity. The standardized and unstandardized path coefficients of Model 2, presented in Figure 1, showed that mothers who displayed more verbal and physical aggression in their marriage were more likely to reciprocate their son's negative emotions and this was true after controlling for fathers' display of verbal and physical aggression in their marriage. No connections were observed between mothers' display of marital conflict and measures of son's emotional reciprocity. Fathers who displayed more verbal and physical aggression toward their wives had sons who were more likely to reciprocate their mother's negative emotion, and this remained true after controlling for mothers' display of verbal and physical aggression toward their husband. No connections were observed between fathers' display of verbal and physical aggression in their marriage and mothers' emotional reciprocity.

Path coefficients between emotional reciprocity measures and boys' outcomes indicated that in dyads with mothers who reciprocated their son's negative emotions, boys were less liked by peers and were more aggressive with peers. There were no connections between mother's reciprocity of son's positive emotion and peer relationship measures. Boys who reciprocated their mother's positive emotions were better liked by peers, whereas boys who reciprocated their mother's negative emotions were more aggressive.

\section{Discussion}

The purpose of the present study was to examine connections between marital conflict and the quality of boys' peer relationships. On the basis of the premises of Davies and Cummings's (1994) emotional security hypothesis, both direct and indirect linkages between marital conflict and children's peer relationships were considered. Specifically, we examined mother-child emotional expressiveness as a potential mediator between marital conflict and children's relationships with peers. Contrary to expectations, no direct connections between marital conflict and children's peer relationships were observed. Instead, the results suggest that marital conflict interferes with the emotional tenor of the mother-son relationship, creating patterns of emotional expressiveness between mother and son that are problematic for the establishment of positive peer relationships. These findings are consistent with the long-standing argument that marital conflict spills over into parents' expression of emotions with children.

Our results join with findings from previous research showing links between marital conflict and the emotional climate of the parent-child relationship (Grych \& Fincham, 1990; Harold \& Conger, 1997; Owen \& Cox, 1997). Such connections are consistent with processes outlined by the emotional security hypothesis. Specifically, according to the emotional security hypothesis, marital conflict interferes with the emotional bond, or attachment relationship, between parent and child. A key aspect of the attachment relationship is the expression of emotions between parent and child, with more positive and responsive patterns of emotional expressiveness promoting children's formation of a secure attachment with parents (Bretherton, 1990). Thus, to the extent that marital conflict creates negative patterns of emotional expression between parent and child, it may interfere with children's sense of security in their relationship to parents. In turn, children may develop a negative internal working model of self and others, which leads children to avoid peer relationships and engage in negative patterns of social behavior. Although the quality of the 


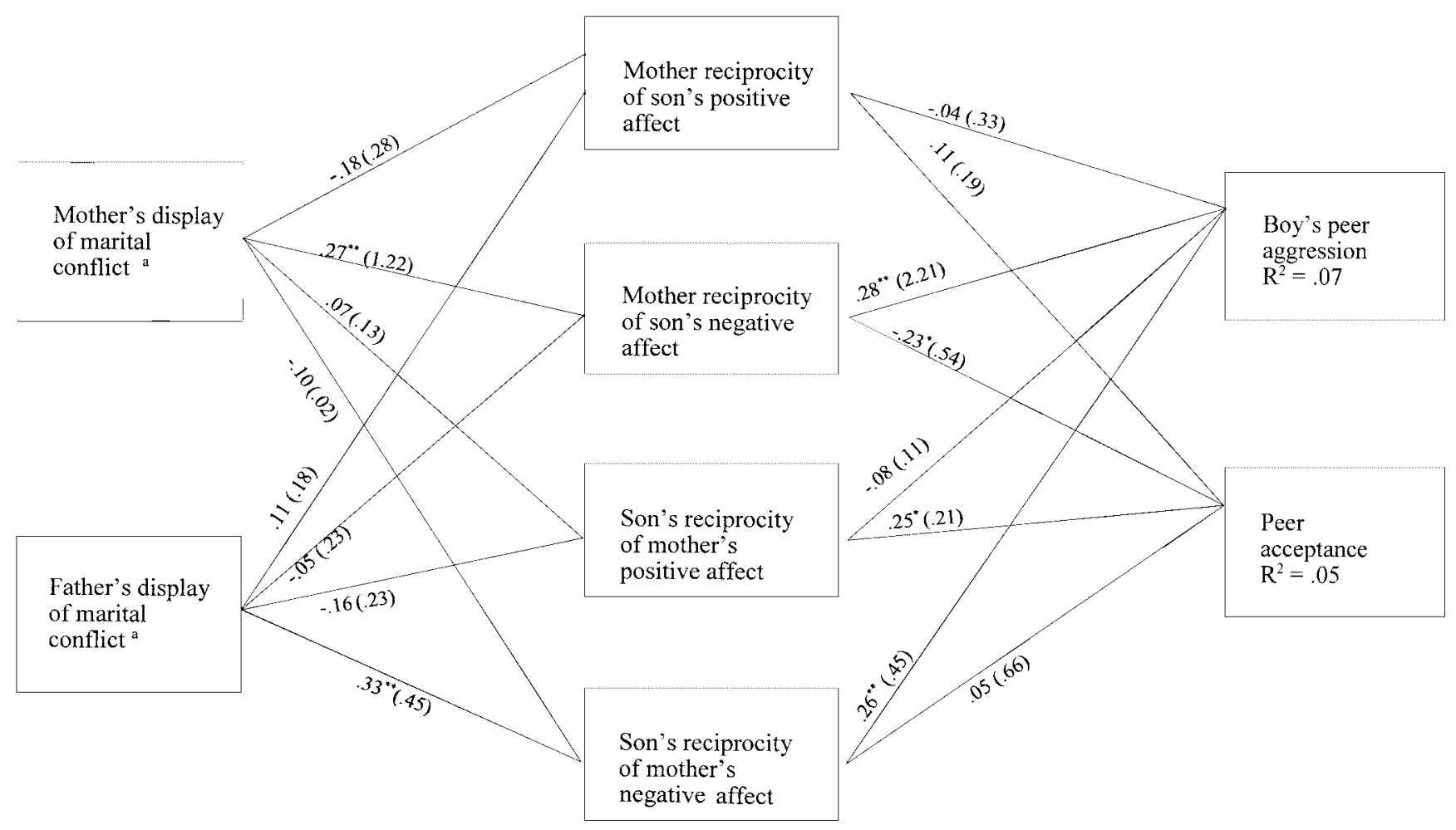

Figure 1. Path model of associations among marital conflict variables, mother-son emotional reciprocity variables, boys' aggression with peers, and boys' peer acceptance. Standardized and unstandardized path coefficients are given. ${ }^{*} p<.05 . * *<.01$. ${ }^{\text {a }}$ Path coefficients between marital conflict and mother-son emotional reciprocity were estimated controlling for marital conflict experienced by the other parent.

mother-child attachment relationship was not assessed in the present study, the connections between marital conflict, mother-son emotional expressiveness, and boys' peer relationships that were found are consistent with the basic premise of the emotional security hypothesis. A direct test of the emotional security hypothesis based on the assessment of both the quality of the parent-child attachment relationship and patterns of emotions expressed between parent and child awaits future research.

It is important to note that it was a particular pattern of emotions expressed between mother and son that mediated the connection between marital conflict and boys' peer relationships, rather than the emotional behavior of either mother or child. These findings support arguments that it is important to take a relationship perspective, which accounts for the contribution of both individuals to the quality of their relationship together, when investigating family processes (Hinde \& Stevenson-Hinde, 1987). It is of interest to note that emotional reciprocity also has been found to play an important role in determining the quality of the marital relationship, with maritally distressed couples being more likely to engage in high levels of negative emotional reciprocity (Gottman, 1979; Levenson \& Gottman, 1983). Although the emotional expressions of husband and wife were not assessed in the current study, when considered with the finding of Gottman and his colleagues (Gottman, 1979; Levenson \& Gottman, 1983), our data suggest that similar patterns of negative emotional reciprocity may be occurring in the marital relationship and parent-child relationships in maritally distressed homes. It may be that mother and son are mirroring patterns of emotional expressiveness they have participated in or observed in the marital relationship. Processes of identification with the same-sex parent may play a role in boys' responses to mothers' emotions, with boys taking the side of their father over their mother in the face of marital conflict and thus engaging in negative patterns of emotional reciprocity with their mother. Mothers, on the other hand, may be transferring negative feelings they have toward their husband to interactions with sons. Alternatively, it is possible that the direction of effect in connections between marital conflict and parent-child emotional reciprocity is reversed, with patterns of negative emotional reciprocity between mother and son causing perturbations in the marital relationship, through the induction of negative mood in mothers. Because our findings are based on concurrent associations between measures, they do not indicate the direction of effect between marital conflict and mother-child emotional reciprocity. Future longitudinal studies are needed to examine emotional expressions within the marital dyad and parent-child dyads in relation 
to marital conflict in order to elucidate the role of family emotional communication in connection between marital conflict and children's adjustment.

The results of this study also are consistent with previous evidence that emotional reciprocity in the parent-child relationship contributes to the quality of children's peer relationships (Carson \& Parke, 1996). It may be that children are learning patterns of emotional responding to their partner's emotions that they carry into their peer relationships. Alternatively, negative patterns of emotional reciprocity between parent and child may interfere with children's emotional regulation, which has been found to be a key component of children's social competence with peers (Eisenberg et al., 1993; Fabes et al., 1999; Rubin et al., 1995). However, unlike Carson and Parke (1996), who found that reciprocal negative affect on the part of fathers, but not mothers, was linked to negative patterns of social behavior in children, we did find connections between mother-son emotional reciprocity and boys' social competence with peers. The discrepancy between our findings and those of Carson and Parke may be due to differences in the interactive contexts in which parent-child interaction were observed. In the Carson and Parke study, parent-child interaction was observed during physical play, a form of play activity in which mothers are less likely to engage with children than fathers (Lamb, 1987; MacDonald \& Parke, 1984; Parke \& Tinsley, 1984). As a result, mothers' behavior may have differed from their typical pattern of interaction. Alternatively, differences in children's ages across the two studies may have contributed to the different findings, in that mothers of preschoolers may be more tolerant of negative emotional displays in children and thus less likely to respond negatively to such displays than mothers of school-age children. Additional research is needed to investigate connections between mother-child and father-child emotional reciprocity and children's peer relationships, in multiple contexts of interaction and with children of different ages.

Although previous studies have established connections between marital conflict and boys' aggressive behavior (Johnson \& O'Leary, 1987; Jouriles, Murphy, \& O'Leary, 1989; Wierson, Forehand, \& McCombs, 1988) and social competence (Emery \& O'Leary, 1984; Long, Forehand, Fauber, \& Brody, 1987), no such associations were observed in the present study. One explanation for this discrepancy may be that the present sample had relatively low levels of marital conflict compared with more representative samples, as suggested by comparisons of husbands' and wives' raw scores on the CTS scales with those reported by Straus (1990). Thus, our ability to detect connections between marital conflict and boys' social competence in the present sample may have been limited by the low levels of marital conflict. In addition, it may be that the concurrent nature of the data in this report contributed to a lack of connections between marital conflict and boys' social competence. Consistent with this possibility, several longitudinal studies have found direct connections between marital conflict and children's peer relationships (Criss, Pettit, Meece, Dodge, \& Bates, 1998; Strassberg et al., 1992).
Alternatively, it may be that the present study's focus on parent perceptions of marital conflict limited the possibility of detecting associations between marital conflict and children's peer outcomes. Grych and Fincham (1990) suggested that children's awareness and perception of marital conflict has more important implications for child functioning than does marital conflict in general. Consistent with this perspective, a number of studies have documented important linkages between children's perceptions of marital conflict and children's adjustment (Grych, Seid, \& Fincham, 1992; Harold et al., 1997; Osborne \& Fincham, 1996) in both normative and high-risk samples (Grych, Fincham, Jouriles, \& McDonald, 2000). Additional research is needed that compares the relative contribution of parent-reported and child-reported marital conflict to children's outcomes, both concurrently and over time.

Several additional limitations of the present study should be noted. First, observations of parent-child interaction were available only for mother-son dyads; thus, only a measure of mother-son reciprocity of positive affect was obtained. Given previous evidence of unique connections between marital conflict and mother-child versus fatherchild relationships (Osborne \& Fincham, 1996; Stocker \& Youngblade, 1999), it is likely that the observed links between marital conflict and mother-son reciprocity of positive affect operate differently in the father-son relationship. Additional research that includes observations of fatherchild interaction is needed. Similarly, the present study focused only on boys. Although evidence suggests that marital conflict may be particularly significant for boys' outcomes (Fauber et al., 1990), it is important to consider how marital conflict affects girls. Finally, the findings of this study are based on concurrent associations between measures and do not indicate the direction of effect between marital conflict, mother-child emotional reciprocity, and boys' peer relationships. Given the primacy of the marital relationship in the family and of parent-child relationships, our interpretations lean toward marital conflict leading to mother-son emotional expressiveness, which in turn influences boys' peer relationships. However, it may be that boys' peer relationships influence the quality of mother-son interaction, which in turn creates turmoil between husband and wife. It will be important for future longitudinal research to address issues concerning the direction of effect in connections between marital conflict, parent-child emotional reciprocity, and children's adjustment.

\section{Implications for Application and Public Policy}

Although it is important to keep in mind the limitations of this investigation, the findings do have noteworthy implications for practitioners. The observed connections between marital conflict and parent-child emotional expressiveness, and the association of these factors with children's peer relationships, offer information pertinent to intervention efforts designed to limit the negative consequences of marital conflict on children's developmental outcomes. Specifically, the findings suggest that in dealing with the impact of marital conflict on children it may be important to help 
parents recognize the need to separate the marital relationship from parent-child relationships. That is, because marital conflict was related to children's peer relationships indirectly, through its association with the quality of emotions expressed between mother and son, intervention efforts that help parents learn to separate experiences in their marriage from emotions expressed in parent-child interaction may be useful in reducing the negative impact of marital conflict on children's relationships outside the family. Furthermore, the links observed between marital conflict, mother-son emotional reciprocity, and boys' peer relationships suggest that intervention efforts should include both mother and father, and parent and child. Specifically, the unique associations between mother's marital conflict and mother's emotional reciprocity, and between father's marital conflict and son's emotional reciprocity with mother, indicate that intervention targeting either parent alone will be less effective in dealing with the negative impact of marital conflict. In addition, given that emotional reciprocity is based on the pattern of emotions expressed between mother and son, intervention efforts including both parent and child may be more effective in changing the emotional climate of the parent-child relationship. Finally, the connections observed between marital conflict, emotional reciprocity, and children's peer relationships offer a more specific focus for intervention efforts than the traditional emphasis on broadband dimensions of affect. Our findings join with other empirical and clinical literature to suggest that by targeting the emotions expressed between parents and children, practitioners may be able to ameliorate the impact of marital conflict on children's adjustment.

\section{References}

Bagwell, C. L., Newcomb, A. F., \& Bukowski, W. M. (1998). Preadolescent friendship and peer rejection as predictors of adult adjustment. Child Development, 69, 140-153.

Bakeman, R. (1991). Analyzing categorical data. In B. M. Montgomery \& S. Duck (Eds.), Studying interpersonal interaction (pp. 255-274). New York: Guilford Press.

Belsky, J., Crnic, K., \& Gable, S. (1995). The determinants of coparenting in families with toddler boys: Spousal differences and daily hassles. Child Development, 66, 629-642.

Bierman, K. L., \& Smoot, D. L. (1991). Linking family characteristics with poor peer relations: The mediating role of conduct problems. Journal of Abnormal Child Psychology, 19, 341-356. Boyum, L. A., \& Parke, R. D. (1995). The role of family emotional expressiveness in the development of children's social competence. Journal of Marriage and the Family, 57, 593-608.

Bretherton, I. (1990). Open communication and internal working models: Their role in the development of attachment relationships. In R. A. Thompson (Ed.), Nebraska Symposium on Motivation: Vol. 36. Socioemotional development: Current theory and research in motivation (pp. 57-113). Lincoln: University of Nebraska Press.

Brody, G. H., Stoneman, Z., \& MacKinnon, C. E. (1986). Contributions of maternal child rearing practices in play contexts to sibling interactions. Journal of Applied Developmental Psychology, 7, 225-236.

Carson, J. L., \& Parke, R. D. (1996). Reciprocal negative affect in parent-child interactions and children's peer competency. Child Development, 67, 2217-2226.
Cohen, J. (1960). A coefficient of agreement for nominal scales. Educational and Psychological Measurement, 10, 37-46.

Coie, J. D., \& Dodge, K. A. (1983). Continuities and changes in children's social status: A five-year longitudinal study. Merrill Palmer Quarterly, 29, 261-282.

Coie, J. D., Dodge, K. A., \& Coppotelli, H. (1982). Dimensions and types of social status: A cross-age perspective. Developmental Psychology, 18, 557-571.

Criss, M. M., Pettit, G. S., Meece, D., Dodge, K. A., \& Bates, J. E. (1998, March). Parenting as a mediator and moderator in the association between marital conflict and child adjustment: A longitudinal study. Poster presented at the biennial conference on Human Development, Mobile, Alabama.

Davies, P. T., \& Cummings, E. M. (1994). Marital conflict and child adjustment: An emotional security hypothesis. Psychological Bulletin, 116, 387-411.

Davies, P. T., \& Cummings, E. M. (1998). Exploring children's emotional security as a mediator of the link between marital relations and child adjustment. Child Development, 69, 124-139.

Deal, J. E., Halverson, C. F., \& Wampler, K. S. (1989). Parental agreement on child-rearing orientations: Relations to parental, marital, family, and child characteristics. Child Development, 60, $1025-1034$

Denham, S., Renwick-DeBardi, S., \& Hewes, S. (1994). Emotional communication between mothers and preschoolers: Relations with emotional competence. Merrill-Palmer Quarterly, 40, 488508.

Dodge, K. A., McClaskey, C. L., \& Feldman, E. (1985). Situational approach to the assessment of social competence in children. Journal of Consulting and Clinical Psychology, 53, 344353.

Dunn, J., Slomkowski, C., \& Beardsall, L. (1994). Sibling relationships from the preschool period through middle childhood and early adolescence. Developmental Psychology, 30, 315-324.

Eisenberg, N., Fabes, R. A., Bernzwieg, J., Karbon, M., Poulin, R., $\&$ Hanish, L. (1993). The relations of emotionality and regulation to preschooler's social skills and sociometric status. Child Development, 64, 1418-1438.

Eisenberg, N., Fabes, R., Schaller, M., Carlo, G., \& Miller, P. (1991). The relations of parental characteristics and practices to children's vicarious emotional responding. Child Development, 62, 1393-1408.

Emery, R. E., \& O'Leary, K. D. (1984). Marital discord and child behavior problems in a nonclinical sample. Journal of Abnormal Child Psychology, 12, 411-420.

Erel, O., \& Burman, B. (1995). Interrelatedness of marital relations and parent-child relations: A meta-analytic review. Psychological Bulletin, 118, 108-132.

Fabes, R. A., Eisenberg, N., Jones, S., Smith, M., Guthrie, I., Poulin, R., Shepard, S., \& Friedman, J. (1999). Regulation, emotionality, and preschoolers' socially competent peer interactions. Child Development, 70, 432-442.

Fauber, R., Forehand, R., Thomas, A. M., \& Wierson, M. (1990). A mediational model of the impact of marital conflict on adolescent adjustment in intact and divorced families: The role of disrupted parenting. Child Development, 61, 1112-1123.

Fincham, F. D. (1998). Child development and marital relations. Child Development, 69, 543-574.

Gottman, J. M. (1979). Detecting cyclicity in social interaction. Psychological Bulletin, 86, 338-348.

Gottman, J., \& Katz, L. F. (1989). The effects of marital discord on young children's peer interaction and health. Developmental Psychology, 25, 373-381.

Grych, J. H., \& Fincham, F. D. (1990). Marital conflict and 
children's adjustment: A cognitive-contextual framework. Psychological Bulletin, 108, 267-290.

Grych, J. H., Fincham, F. D., Jouriles, E. N., \& McDonald, R. (2000). Interparental conflict and child adjustment: Testing the mediational role of appraisals in the cognitive-contextual framework. Child Development, 71, 1648-1661.

Grych, J. H., Seid, M., \& Fincham, F. D. (1992). Assessing marital conflict from the child's perspective: The children's perception of interparental conflict scale. Child Development, 63, 558-572. Harold, G. T., \& Conger, R. (1997). Marital conflict and adolescent distress: The role of adolescent awareness. Child Development, 68, 333-350.

Harold, G. T., Fincham, F. D., Osborne, L. N., \& Conger, R. D. (1997). Mom and dad are at it again: Adolescent perceptions of marital conflict and adolescent psychological distress. Developmental Psychology, 33, 333-350.

Hart, C. H., Ladd, G. W., \& Burleson, B. R. (1990). Children's expectations of the outcomes of social strategies: Relations with sociometric status and maternal disciplinary styles. Child Development, 61, 127-137.

Hartup, W. W. (1979). The two social worlds of childhood. American Psychologist, 34, 944-950.

Hinde, R. A., \& Stevenson-Hinde, J. (1987). Interpersonal relationships and child development. Developmental Review, 7, $1-21$.

Jenkins, J. (2000). Marital conflict and children's emotions: The development of an anger organization. Journal of Marriage and the Family, 62, 723-736.

Johnson, P. L., \& O'Leary, K. D. (1987). Parental behavior patterns and conduct disorder in girls. Journal of Abnormal Child Psychology, 15, 573-581.

Jouriles, E. N., \& Farris, A. M. (1992). Effects of marital conflict on subsequent parent-son interactions. Behavior Therapy, 23, 355-374.

Jouriles, E. N., Farris, A. M., \& McDonald, R. (1991). Marital functioning and child behavior: Measuring specific aspects of the marital relationship. In J. P. Vincent (Ed.), Advances in family intervention, assessment, and theory (Vol. 5, pp. 25-46). Greenwich, CT: JAI Press.

Jouriles, E. N., Murphy, C. M., \& O’Leary, K. D. (1989). Interspousal aggression, marital discord, and child problems. Journal of Consulting and Clinical Psychology, 57, 453-455.

Katz, L. F., \& Gottman, J. M. (1995). Marital interaction and child outcomes: A longitudinal study of mediating and moderating processes. In D. Cicchetti \& S. L. Toth (Eds.), Rochester symposium on developmental psychopathology: Vol. 6. Emotion, cognition, and representation. (pp. 301-342). Rochester, NY: University of Rochester Press.

Kerig, P. K., Cowan, P. A., \& Cowan, C. P. (1993). Marital quality and gender differences in parent-child interaction. Developmental Psychology, 29, 931-939.

Kupersmidt, J. B., \& Coie, J. D. (1990). Preadolescent peer status, aggression, and school adjustment as predictors of externalizing problems in adolescence. Child Development, 61, 1350-1362.

Lamb, M. E. (1987). The emergent American father. In M. E. Lamb (Ed.), The father's role: Cross-cultural perspectives (pp. 3-25). Hillsdale, NJ: Erlbaum.

Levenson, R. W., \& Gottman, J. M. (1983). Marital interaction: Physiological linkage and affective exchange. Journal of Personality and Social Psychology, 45, 587-597.

Levenson, R. W., \& Gottman, J. M. (1985). Physiological and affective predictors of change in relationship satisfaction. Journal of Personality and Social Psychology, 49, 85-94.

Lindsey, E. W., \& Mize, J. (2001). Interparental agreement, parent-child responsiveness, and children's peer competence. Family Relations, 50, 348-354.

Long, N., Forehand, R., Fauber, R., \& Brody, G. (1987). Selfperceived and independently observed competence of young adolescents as a function of parental marital conflict and recent divorce. Journal of Abnormal Child Psychology, 15, 15-27.

Maccoby, E. E., \& Martin, J. A. (1983). Socialization in the context of the family: Parent-child interaction. In E. M. Hetherington (Ed.) and P. H. Mussen (Series Ed.), Handbook of child psychology: Vol. 4. Socialization, personality, and social development (pp. 1-101). New York: Wiley.

MacDonald, K., \& Parke, R. (1984). Bridging the gap: Parentchild play interaction and interactive competence. Child Development, 55, 1265-1277.

MacKinnon-Lewis, C., Lamb, M. E., Arbuckle, B., Baradaran, L. P., \& Volling, B. L. (1992). The relationship of biased maternal and filial attributions and the aggressiveness of their interactions. Development and Psychopathology, 4, 403-415.

MacKinnon-Lewis, C., Rabiner, D., \& Starnes, R. (1999). Predicting boys' social acceptance and aggression: The role of motherchild interactions and boys' beliefs about peers. Developmental Psychology, 35, 632-639.

MacKinnon-Lewis, C., Volling, B. L., Lamb, M. E., Dechman, K., Rabiner, D., \& Curtner, M. E. (1994). A cross-contextual analysis of boys' social competence: From family to school. Developmental Psychology, 30, 325-333.

Osborne, L. N., \& Fincham, F. D. (1996). Marital conflict, parentchild relationships, and child adjustment: Does gender matter? Merrill Palmer Quarterly, 42, 48-75.

Owen, M. T. \& Cox, M. J. (1997). Marital conflict and the development of infant-parent attachment relationships. Journal of Family Psychology, 11, 152-164.

Parke, R. D., Burks, V. M., Carson, J. L., Neville, B., \& Boyum, L. A. (1994). Family-peer relationships: A tripartite model. In R. D. Parke \& S. G. Kellam (Eds.), Exploring family relationships with other social contexts (pp. 115-145). Hillsdale, NJ: Erlbaum.

Parke, R. D., Cassidy, J., Burks, V. M., Carson, L. J., \& Boyum, L. (1992). Familial contribution to peer competence among young children: The role of interactive and affective processes. In R. D. Parke \& G. W. Ladd (Eds.), Family-peer relationships: Modes of linkage (pp. 17-44). New York: Brunner/Mazel.

Parke, R. D., Kim, M., Flyr, M., McDowell, D. J., Simpkins, S. D., Killian, C. M., \& Wild, M. (2001). Managing marital conflict: Links with children's peer relationships. In J. H. Grych \& F. D. Fincham (Eds.), Interparental conflict and child development (pp. 291-314). Cambridge, England: Cambridge University Press.

Parke, R. D., \& Ladd, G. W. (1992). Family-peer relationships: Modes of linkage. Hillsdale, NJ: Erlbaum.

Parke, R. D., MacDonald, K., Burks, V., Carson, J., Bhavnagri, N., Barth, J., \& Beitel, A. (1989). Family and peer systems: In search of the linkages. In K. Kreppner \& R. M. Lerner (Eds.), Family systems and life-span development (pp. 65-92). Hillsdale, NJ: Erlbaum.

Parke, R. D., \& Tinsley, B. R. (1984). Fatherhood: Historical and contemporary perspectives. In K. McClusky \& H. Reese (Eds.), Life span development: Historical and generational effects. New York: Academic Press.

Parker, J. G., \& Asher, S. (1987). Peer relations and later personal adjustment: Are low-accepted children at risk? Psychological Bulletin, 102, 357-389.

Parker, J. G., Rubin, K. H., Price, J. M., \& DeRosier, M. E. (1995). Peer relationships, child development, and adjustment: A devel- 
opmental psychopathology perspective. In D. Cicchetti \& D. J. Cohen (Eds.), Developmental psychopathology. Vol. II: Risk, disorder, and adaptation (pp. 96-161). New York: Wiley.

Pedhazur, E. J. (1982). Multiple regression in behavioral research: Explanation and prediction (2nd ed.). New York: Holt, Rinehart, \& Winston.

Putallaz, M. (1987). Maternal behavior and children's sociometric status. Child Development, 58, 324-340.

Rothbaum, F., \& Weisz, J. R. (1994). Parental caregiving and child externalizing behavior in nonclinical samples: A meta-analysis. Psychological Bulletin, 116, 55-74.

Rubin, K. H., Coplan, R. J., Fox, N. A., \& Calkins, S. D. (1995). Emotionality, emotion regulation, and preschoolers' social adaptation. Development \& Psychopathology, 7, 49-62.

Snyder, J. R. (1998). Marital conflict and child adjustment: What about gender? Developmental Review, 18, 390-420.

Stocker, C. M., \& Youngblade, L. (1999). Marital conflict and parental hostility: Links with children's sibling and peer relationships. Journal of Family Psychology, 13, 598-609.

Strassberg, Z., Dodge, K. A., Bates, J. E., \& Pettit, G. S. (1992). The longitudinal relation between parental conflict strategies and children's sociometric standing in kindergarten. Merrill-Palmer Quarterly, 38, 477-493.
Straus, M. A. (1979). Measuring intrafamily conflict and violence: The Conflict Tactics (CT) scales. Journal of Marriage and the Family, 41, 75-88.

Straus, M. A. (1990). Measuring intrafamily conflict and violence: The Conflict Tactics (CT) scales. In M. A. Straus \& R. J. Gelles (Eds.), Physical violence in American families: Risk factors and adaptations to violence in 8,145 families (pp. 29-45). Piscataway, NJ: Transaction.

Wentzel, K. R., \& Asher, S. R. (1995). The academic lives of neglected, rejected, popular, and controversial children. Child Development, 66, 754-763.

Wierson, M., Forehand, R., \& McCombs, A. (1988). The relationship of early adolescent functioning to parent-reported and adolescent-perceived interparental conflict. Journal of Abnormal Child Psychology, 16, 707-718.

Youniss, J. (1980). Parents and peers in social development: A Sullivan-Piaget perspective. Chicago: University of Chicago Press.

Brody, G. H., Stoneman, Z., \& MacKinnon, C. E. (1986). Contri

Received September 20, 1999 Revision received April 29, 2002

Accepted April 29, 2002

\section{American Psychological Association SUBSCRIPTION Claims INFORMATION}

Today's Date:

We provide this form to assist members, institutions, and nonmember individuals with any subscription problems. With the appropriate information we can begin a resolution. If you use the services of an agent, please do NOT duplicate claims through them and directly to us. PLEASE PRINT CLEARLY AND IN INK IF POSSIBLE.

\begin{tabular}{lll}
\hline PRINT FULL NAME OR KEY NAME OF INSTITUTION & & \\
\hline ADDRESS & & \\
\hline CITY & STATE/COUNIRY & ZIP
\end{tabular}

YOUR NAME AND PHONE NUMBER
MEMBER OR CUSTOMER NUMBER(MAY BE FOUND ON ANY PAST ISSUE LABEL) DATE YOUR ORDER WAS MAILED (OR PHONED)

PREPAID CHECK/CARD CLEARED DATE: $_{\text {CHECK }}$

(If possible, send a copy, front and back, of your cancelled check to help us in our research of your claim.)

ISSUES: DAMAGED
TITLE

Thank you. Once a claim is received and resolved, delivery of replacement issues routinely takes 4-6 weeks.

\section{NUMBER OR MONTH}

VOLUME OR YEAR
DATE RECEIVED:

ACTION TAKEN:

STAFF NAME:
DATE OF ACTION:

INV. NO. \& DATE:

LABEL NO. \& DATE:

Send this form to APA Subscription Claims, 750 First Street, NE, Washington, DC 20002-4242

PLEASE DO NOT REMOVE. A PHOTOCOPY MAY BE USED. 